\title{
Preliminary Geophysical Investigation of Igbajo Archaeological Site, Southwestern Nigeria
}

\author{
Rereloluwa Bello $^{1}$, Micheal Oladunjoye ${ }^{2}$, Toluwaleke Ajayi ${ }^{1}$ \\ Department of Earth and Physical Sciences, Crawford University, Ogun, Nigeria ${ }^{1}$ \\ Department of Geology, University of Ibadan, Oyo State, Nigeria ${ }^{2}$
}

\begin{abstract}
The integration of Ground Penetration Radar (GPR), magnetic and electrical resistivity methods revealed detailed and cost effective identification of zones of potential archaeological interest at the theatre of war in Igbajo. The Ground Penetrating Radar (GPR) were acquired using the GSSI SIR 3000, the magnetic method were acquired using the proton precession magnetometer while Ohmega resistivity was used to acquire the electrical resistivity data. The applications of geophysical method to delineate the depth and locations of archaeological materials have been demonstrated. The result of the magnetic survey showed regions of high magnetic intensity which indicates the existence of certain buried artifacts; this assisted in the gridding of the Ground Penetrating Radar (GPR) profiles. Significant features were observed on the radargram which correlates with high resistivity anomalies observed on the inversion profile. It was observed that a region of high resistivity values on the inversion coincides with the ground penetrating radar on the radargram. The results show that the region with the highest resistivity between $510-54959$ $\mathrm{Ohm}-\mathrm{m}$ and at depths between $0.5-3 \mathrm{~m}$ from the resistivity inversion indicates the possible presence of artifacts which can further be confirmed through excavation
\end{abstract}

Keywords: Ground Penetrating Radar (GPR), geophysical, Geophysical Survey Systems, Inc. (GSSI), GPS

\section{INTRODUCTION}

About 130years ago, The Kiriji war was a conflict that happened majorly between the allied forces of Ijesa/Ekiti and Ibadan. It is believed that the war which lasted for 16years with severe casualties showed the biggest array of military hardware in the whole of West Africa. Kiriji was named after earth-like vibrations which gave thunder-like sound from the cannon guns which were used by the Ijeshas and Ekitis giving them more advantage over Ibadan. The Kiriji war was the last war that plagued the entire Yoruba nation. After the peace treaty was signed, the war came to an end. An ancient town known as igbajo provided the camp and terrain for the Latoosa led combatants of Ibadan against the allied forces of Ijesha and Ekiti. Faragbota is a Tree present at the historical sites which was believed to have absorbed bullets, the victims during the war usually hid behind it for protection from opposing enemy. Fejeboju stream was also a mysterious and symbolic stream that was believed to have provided spiritual cleansing for wounded warriors. In view of much blood that flowed into it, the stream turned reddish. The command post of the Ibadan Army commander, Aare Latoosa which was formed out of rocks was still seen at the site.

The outskirt of Igbajo on the Kiriji war theatre appears more of a sacred place; it is now a farmland in its whole entirety. Field observations reveals that there many trenches dugged up to about 6-8 $\mathrm{ft}$ which was used as hideout from opposition enemies. Due to surface erosion, these trenches have now been filled up; it is believed that some of these trenches used as hideouts may have contained war materials and buried artifacts which were buried at some reasonable depth in the subsurface around the camp.

As part of development planning, Environmental impact assessments and Archaeological investigations often require geophysical surveys. These geophysical surveys are mainly designed to define and detect archaeological features and structures that may have been hidden in the subsurface. Geophysical surveys can be used to evaluate and delineate possible hidden sub-surface preservation and extension in cases where there are visible and known archaeological monuments [1]. A geophysical anomaly in a given space, either it is electromagnetic, magnetic, or electrical, could reveal a long list of plausible interpretations, which is due to the subsoil being a heterogeneous media. The basis of archaeological geophysics lies in its ability as a tool to map, locate, and produce images of buried materials. Archaeologist uses geophysical technique to preserve the cultural heritage and also to study it. [2][3] Described the early history and development of the techniques for archaeological investigation.

The non-destructive identification of relics and features buried at archaeological sites is referred to as Archaeological prospection. The research of buried structures in archaeological sites requires a well detailed and comprehensive 


\title{
International Advanced Research Journal in Science, Engineering and Technology
}

\author{
Vol. 6, Issue 4, April 2019
}

knowledge of the shallow subsurface and a methodological technique designed to define and identify areas of interest where successive excavation and surface data collection can be easily planned [4]. This research involves the need for the recovery of the relics of war at the Kiriji war site and for this reason the integrated geophysical techniques of GPR, Magnetics and Electrical methods have been applied. In the magnetic survey, the proton precession magnetometer was used and was interpreted using Oasis Montaj, GSSI SIR 3000 was used for the GPR and processed using RADAN7 and the electrical resistivity method, Omega campus tetrameter was used and was processed with RES2DINV inversion. GPR data was processed into radargrams, Magnetic data was subsequently processed into maps, and electrical data into inversion profiles which were used to further determine the possible presence of artifacts at the study area. In archeological site investigation, the application of integrated geophysical methods is meant to locate depth of buried artifacts, image the subsurface structures, and the positions of these artifacts.

\section{PROBLEM STATEMENT}

The study area is the camp for the Latoosa led Ibadan combatants against the allied forces of Ijesa and Ekiti. There is no detailed information about the distribution of relics of war materials around the camp which prompted the study. This research attempts the integration of Ground Penetrating Radar (GPR), magnetic, and electrical methods to investigate Igbajo archaeological site while also serving as a pre-excavation guide. The research was carried out to determine the depth of burial of artifacts at the site, the presence of buried artifacts, and composition of various trenches at the site and to evaluate the efficiency of magnetics, ground penetrating radar and the electrical resistivity methods in archeological site investigation.

\section{LOCATION OF STUDY AREA}

Theatre of war at Igbajo in Osun state is the study area and it is located within the Basement Complex Terrain of Southwest, Nigeria. It lies within Latitudes $07^{0} 52^{1} 25.7 \mathrm{~N}$ to $07^{0} 52^{1} 14.5 \mathrm{~N}$ and Longitudes $04^{0} 49^{1} 21.6 \mathrm{E}$ to $04^{0} 49^{1} 6.5$ E within Igbajo town. (Fig 1) below shows the towns surrounding and leading to Igbajo. The site consists of range of hills and adjacent valleys and its environs are strategically defensible due to surrounding rugged terrain with rock outcrops.

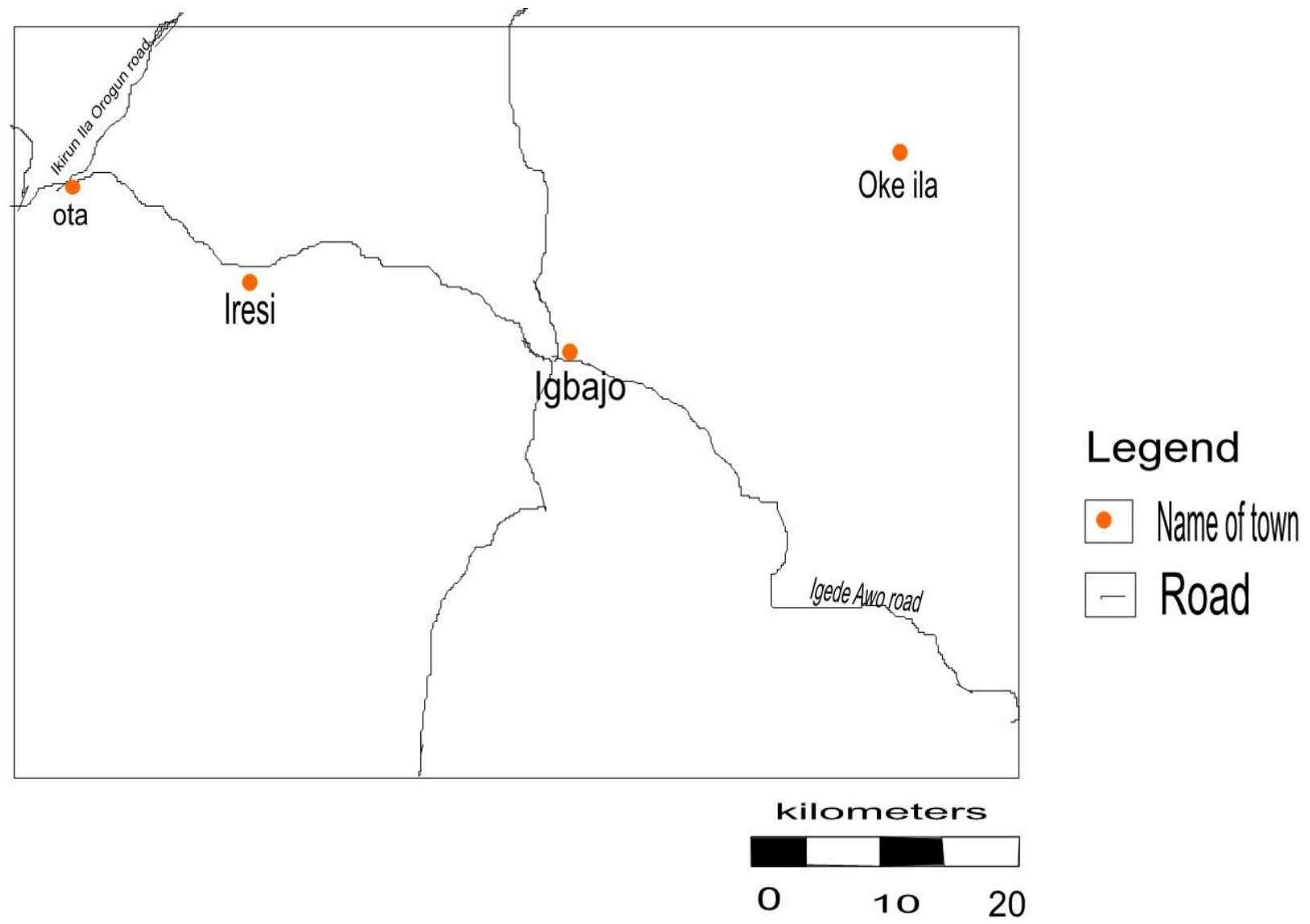

Fig.1: Study area and its surrounding environs 


\section{International Advanced Research Journal in Science, Engineering and Technology}

Vol. 6, Issue 4, April 2019

\section{GEOLOGY OF THE STUDY AREA}

The major tectonic events in the study area shows imprints of all kinds [5] and ranges to Hornblende-granitebiotite,muscovite-granite-tourmaline-gneiss,biotite-gneiss- granite, gneiss, variably migmatised gneisses and pegmatititc intrusions. The dominant rock in the study area is Quartz schist and Quartz and variably Biotite-garnetschist gneiss and biotite-garnet-schist and. (Fig 2) shows the geologic map of the study area

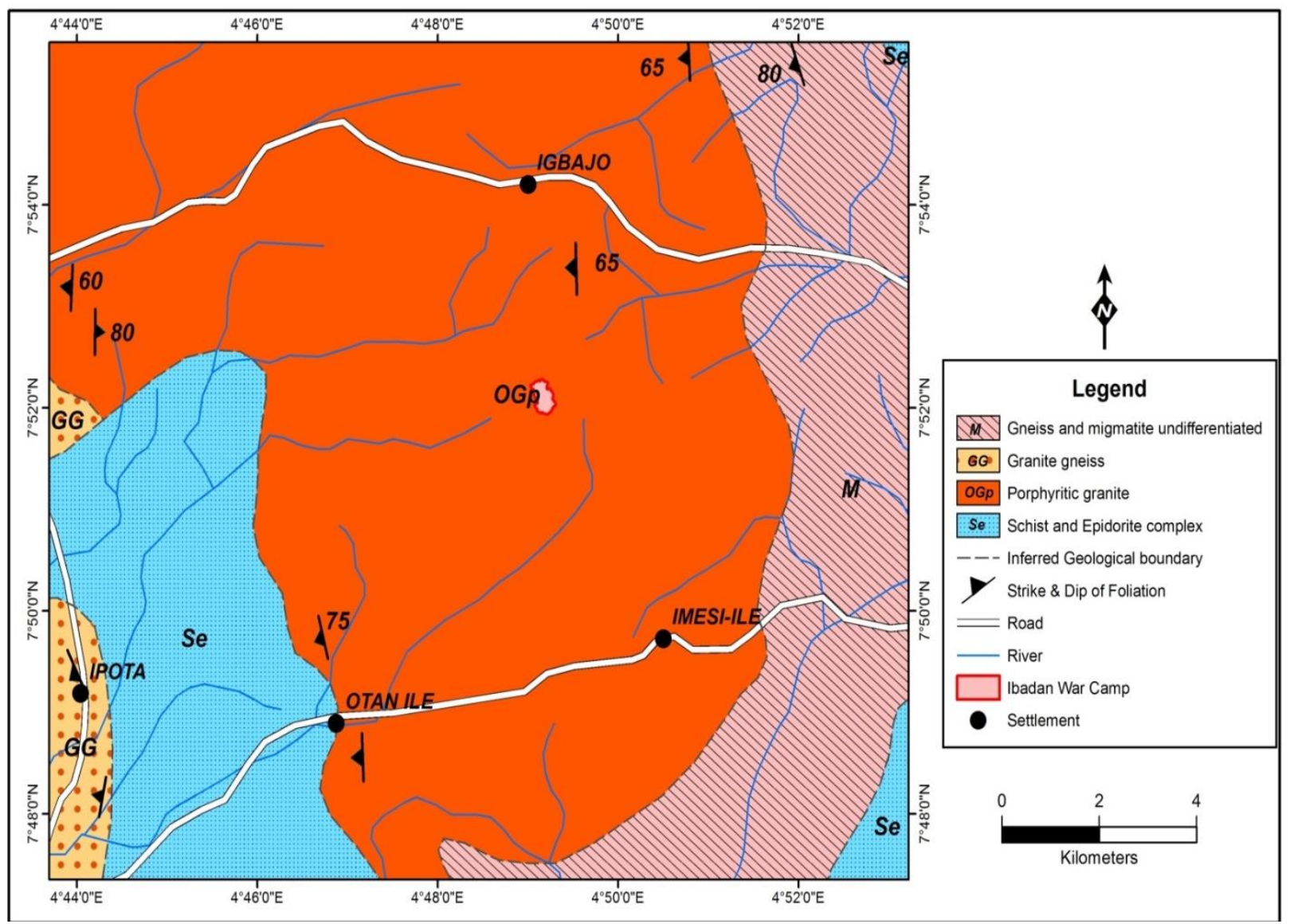

Fig 2 Geologic Map of the Study Area

\section{METHODOLOGY}

\section{A. MAGNETIC SURVEY}

The magnetic survey covers about 400m in the W-E direction and 400m in N-S direction at the theatre of Igbajo war, Osun state. Proton precession magnetometer was used to record total field magnetic readings. GPS was used to determine survey direction and station locations. Coordinates of trenches at the war site were also recorded. The total length of the surveyed lines is approximately $0.4 \mathrm{~km}$. Nineteen (19) profiles involving seven in the N-S direction and twelve in the E-W direction were established. $5 \mathrm{~m}$ Station interval was maintained across each profiles making a data density of 1162 points.

During the survey, the magnetic sensor was oriented north while the magnetic survey staff was maintained at $0.3 \mathrm{~m}$ above the ground. The coordinates of the starting and ending points of each traverse were recorded by GPS in order to create a plot of the survey area using Surfer software. At about $100.0 \mathrm{~m}$ away from the survey area, a base station was set up. At the time interval of one (1) minute, magnetic readings where taking in order to remove the effect of diurnal variation via earth's magnetic field from the survey measurements. The standard survey sensor i.e the top sensor was positioned $1.25 \mathrm{~m}$ vertically above the gradiometer sensor i.e the lower sensor. The lower sensor was raised to a height of $0.30 \mathrm{~m}$ above the ground. This was to increase its sensitivity to the very near-surface magnetic sources[6]. This set up then means recording both the vertical gradient of the total field data at the heights and the total field data of $1.25 \mathrm{~m}$ and $0.30 \mathrm{~m}$ respectively. The station number and line number were then set since each measurement is designated in the console memory by its station and line numbers. During the magnetic reading measurement, the gradiometer assembly was positioned in such a way that the north arrow points to the magnetic north in order to ensure linkage in 


\author{
Vol. 6, Issue 4, April 2019
}

highest magnetic flux between the geomagnetic field and the internal coils of the magnetometer sensors. The first reading is usually taken at the base station. The field magnetic measurements then commenced on the grid lines beginning from a point and later progressed to other points. At the end of line one(1), the line number would be changed to line two(2) by pressing TIME key on the console followed by SHIFT key, then 002, and ENTER key in sequence. Subsequently, readings were then recorded against the new line number and its corresponding station numbers. At the end of line two, the circle would be repeated by changing the line number to 003 and taking the second base station measurement before starting the field measurements on the new line. This sequence was repeated until the entire area was covered, with every odd number line bearing extra reading at the beginning of the profile.

\title{
B. GROUND PENETRATING RADAR SURVEY
}

SIR- 3000 manufactured by Geophysical Survey Systems, Inc. (GSSI) was the GPR system used in this research. The SIR-3000 is a portable, lightweight, single-channel ground penetrating radar system that is used for a wide variety of geological and geophysical applications. The various components of the SIR-3000 are described below. The major external features of the control unit are the keypad, connector panel, color SVGA video screen, indicator lights and battery slot. The video screen allows you to view data in playback mode and in real time. It is readable in bright sunlight. SIR-3000 system contains the following items: 2 Batteries (10.8 V Lithium-Ion rechargeable batteries), 1 Transit Case, 1 Charger, 1 AC Adaptor and a shielded antenna unit with $400 \mathrm{MHz}$ central frequency (Fig 3\&4). The digital control unit and shielded antenna were mounted on a cart and push along the site. The rate at which radar pulses were transmitted was set by the speed of the wheel while the GSSI $400 \mathrm{MHz}$ shielded antenna was used with a cart for this survey. GPR instrument was calibrated around the war theatre to check its suitability for the intended geophysical investigation. Data were collected at a 30 meter line separation along the survey area. Sixteen (16) profiles were recorded and stored; nine profiles in N-S direction and seven profiles in the E-W direction and the results were processed using Radan7 software. A GPS device was also used to track the locations of the survey lines and to mark positions of some features that might introduce anomaly to the radargram.

Data collection with GPR equipment is relatively rapid comparing other geophysical methods and the equipment is made compactable with different terrains. A survey cart is available to push the equipment through a rugged terrain and could be dragged along an established survey line or profiles when the terrain is flat or not rugged. In the course of this survey, a wheel cart was used which enhanced the fastness of the investigation. An odometer is attached to the equipment, which can be used to measure the distance covered, although a measurement tape was also employed during this survey to measures distances of some prominent landmarks.

Two basic profiles were established; East-west directions and the North-south. The direction of each profile was noted, this is especially useful during processing and interpretation of the radargram. (Fig 5) showing the profile lines .The survey area covered about $400 \mathrm{~m}$ by $400 \mathrm{~m}$ at the theatre of war; sixteen profiles were recorded at $30 \mathrm{~m}$ spacing/interval, nine profiles in N-S direction and seven profiles in the E-W direction in order to enhance processing, analysis and interpretation of the result. A total of four field personnel were involved in this survey. This is because of the large expanse of the site and the basic demands of the survey. A two-man team had to clear paths to be able to push through the GPR, the third person on the team pushes the GPR equipment with $400 \mathrm{MHz}$ ground coupled antenna along the survey area. (Fig 3\&4) show the data collection exercise at the theatre of war Igbajo. Operation of mobile phones close to the antenna was avoided in the course of this survey.

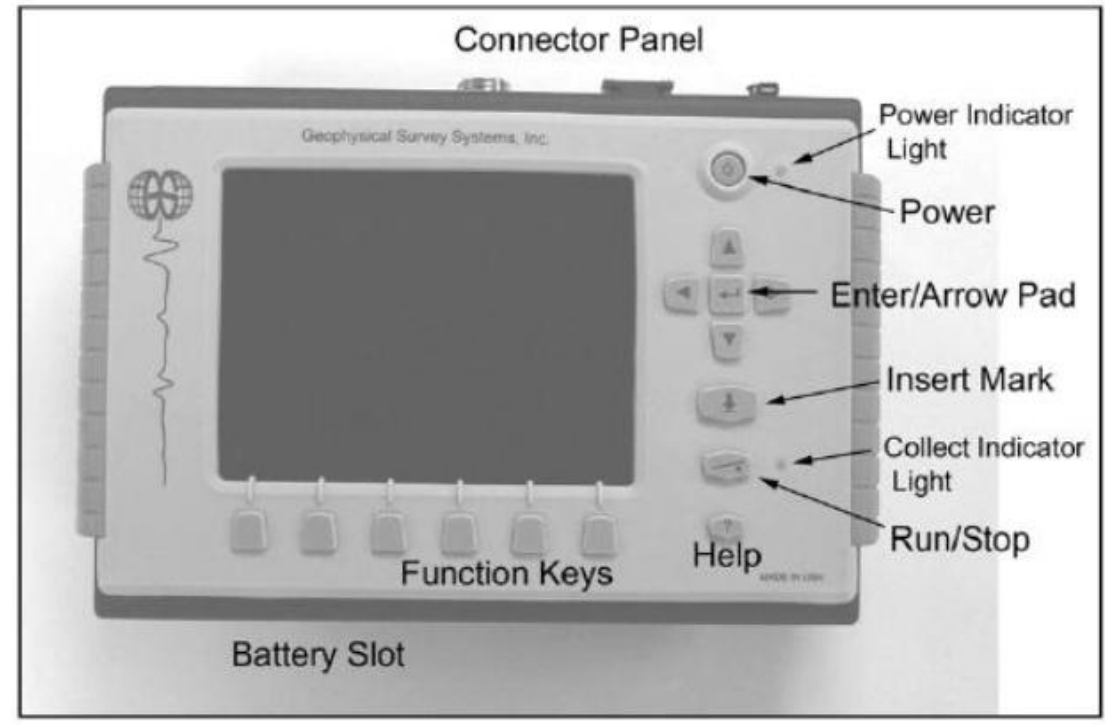

Fig 3 front view of digital control unit [1] modified from GSSI 


\section{International Advanced Research Journal in Science, Engineering and Technology}

Vol. 6, Issue 4, April 2019

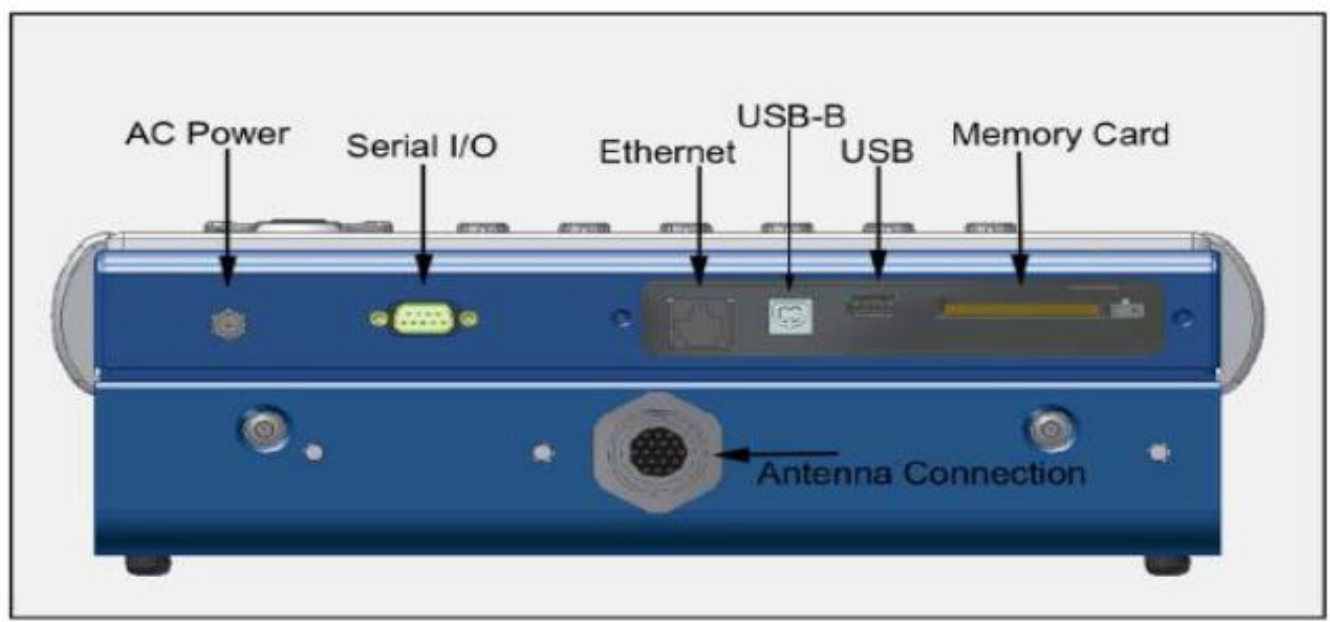

Fig 4 back view showing connection ports [1] modified from GSSI

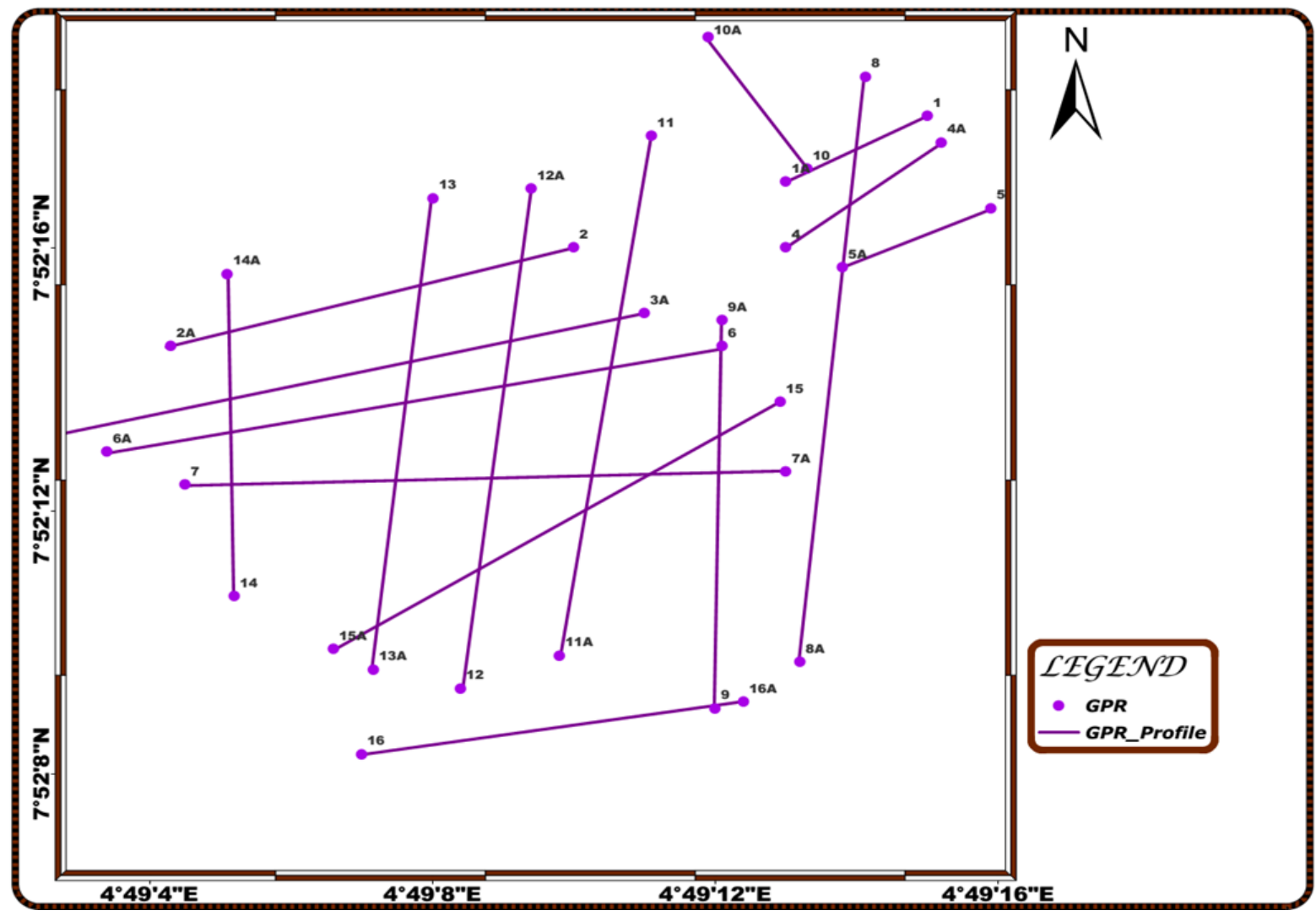

Fig 5 GPR profile line

\section{ELECTRICAL RESISTIVITY SURVEY}

Variations in resistivity are known to correlate effectively with the lithological nature of the earth materials and have been used as a tool in surface and subsurface stratigraphic characterization, thus providing significant information in order to locate and identify buried archaeological materials. Resistivity surveying on archaeological sites indicates spatial differences in sediment moisture: the presence of features, activity areas, architecture and other archaeological remains can be identified if the amount of moisture retained by them is different from the one retained by surrounding sediment. Location of these contrasts or anomalies entails careful and detailed measurement of the sediment resistivity discrete points on the surface along each traverses or grid point. Data collected are usually displayed as profiles or contour maps. Because of the amount of data involved, a computer is an invaluable assistant. The data are then computer-enhanced and interpreted, and areas of potential archaeological interest are located. 
The survey was done with an Ohmega resistivity meter using the Wenner array. A total of five profiles were surveyed, the length of the 2D traverses ranges from a minimum of $84 \mathrm{~m}$ to a maximum of $150 \mathrm{~m}$, the inter electrode spacing was at $3 \mathrm{~m}$ apart and measurements taken at four levels. Profiles 4, 2 were conducted in the E-W direction; profiles 3, 5 were conducted in the N-S direction and profile 1 in the N-W. RES2DINV was used in the inversion of the 2D apparent resistivity data. The survey technique used for this study is the Wenner technique. The Wenner array is relatively sensitive to vertical changes in the subsurface resistivity below the center of the array. However, it is less sensitive to horizontal changes in the subsurface resistivity. In general, the Wenner is good in resolving vertical changes (i.e. horizontal structures), but relatively poor in detecting horizontal changes (i.e. narrow vertical structures). The Wenner array is an attractive choice for a survey carried out in a noisy area (due to its high signal strength) and also if good vertical resolution is required. In this case the survey, five profiles was selected based on results of GPR and magnetic maps. The electrodes spacing remained constant and moved along profiles of maximum of 120 meters. The Wenner configuration was used using electrode spacing of $3 \mathrm{~m}$. This is because, in general most archaeological work does not extend beyond the depth of $5 \mathrm{~m}$ only on exceptional case where serious excavation of earth material has to be done.

\section{RESULTS AND DISCUSSON}

The result of the integrated geophysical investigation which includes the magnetic maps, the ground penetrating radar profiles presented as radargram and the electrical resistivity inversion profiles are presented below

\section{i. Magnetics}

The total magnetic intensity (TMI) is a combination of total signal (both the anomalous and the common signal) of an area. In the study area, the TMI was found to range from 233.74-282 nT with the highest magnetic readings on the north-western part of the map (Fig 6). The map which has different color aggregate signifies the variation of the magnetic intensity in the study area. The area is marked by high (pink color) and low (blue color) magnetic signatures. The variation in magnetic intensity could be as a result of variation in depth, difference in magnetic susceptibility or as a result of shallow buried artifacts in the study area.

The use of the analytic signal amplitude [7][8] poses some attractive features for any type of magnetic prospecting. In terms of geophysical property, it is advantageous that it peaks exactly over the edge of the buried dipping contact that causes the magnetic anomaly [7].The Analytic Signal [9] shows several highs due to the presence of buried structures. In particular, intense highs are more concentrated in the northwestern direction of the study area (Fig 7). The analytic signal generates a maximum directly over discrete bodies as well as their edges. Archaeological magnetic data using the analytic signal showed several suspected features that might be of archaeological interest. Within the analytic map we can notice a major anomaly in the NE, NW, SE and SW directions. It therefore shows the possible presence of buried artifacts within the subsurface. Other geomagnetic anomalies are located along the southeastern side of the map in good agreement with ground penetrating radar and electrical anomalies. Coordinates of trenches at the study area was superimposed on the magnetic map to know which of the trenches falls on the region of high magnetic susceptibility (Fig 8).
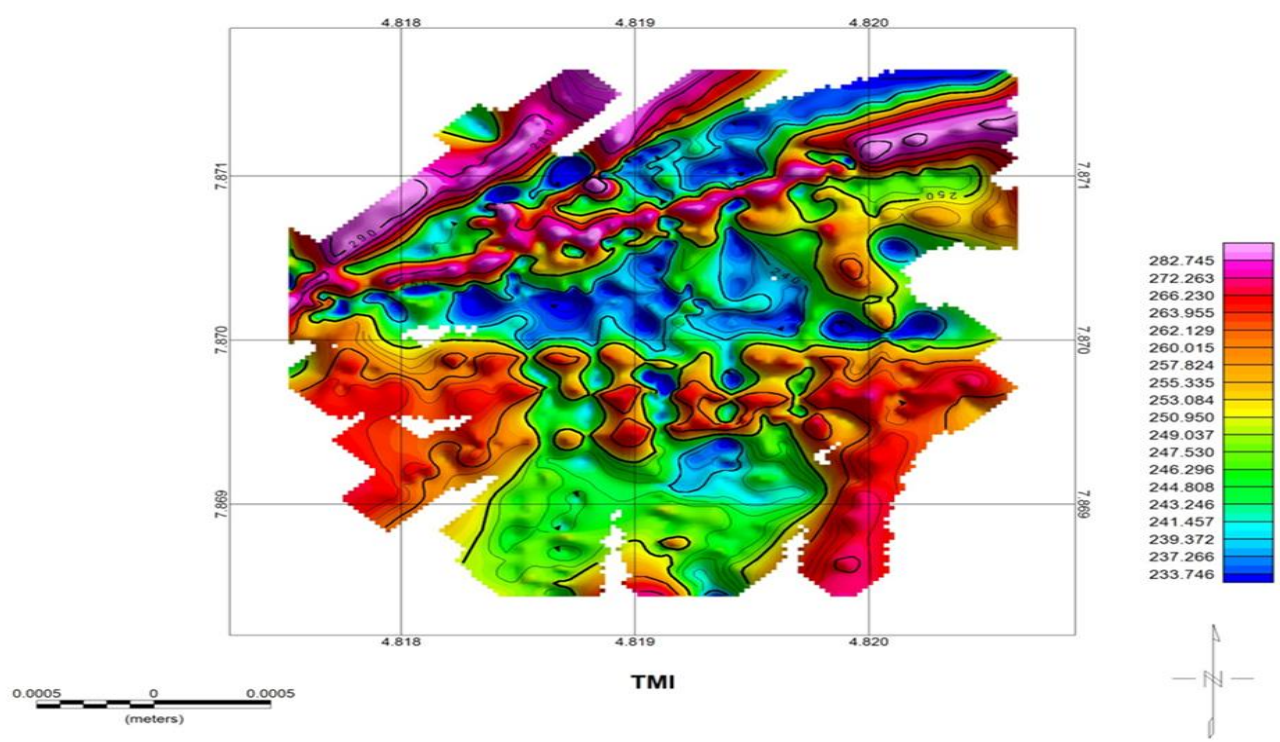

Fig 6: Contoured total magnetic intensity map 


\section{International Advanced Research Journal in Science, Engineering and Technology}

Vol. 6, Issue 4, April 2019

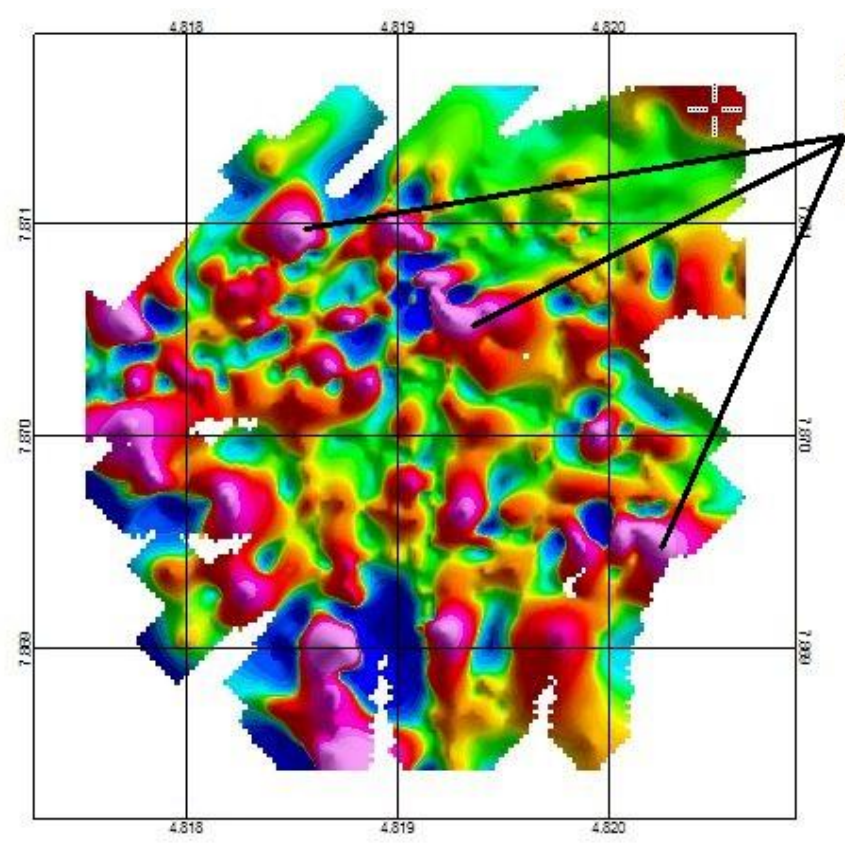

Possible presence of archeological

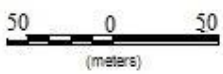

analytic signal map materials

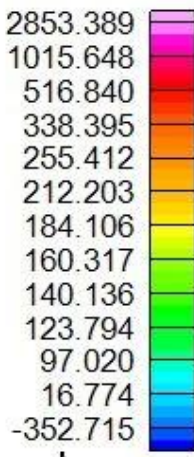

Fig 7: Analytic signal map from Oasis Montaj
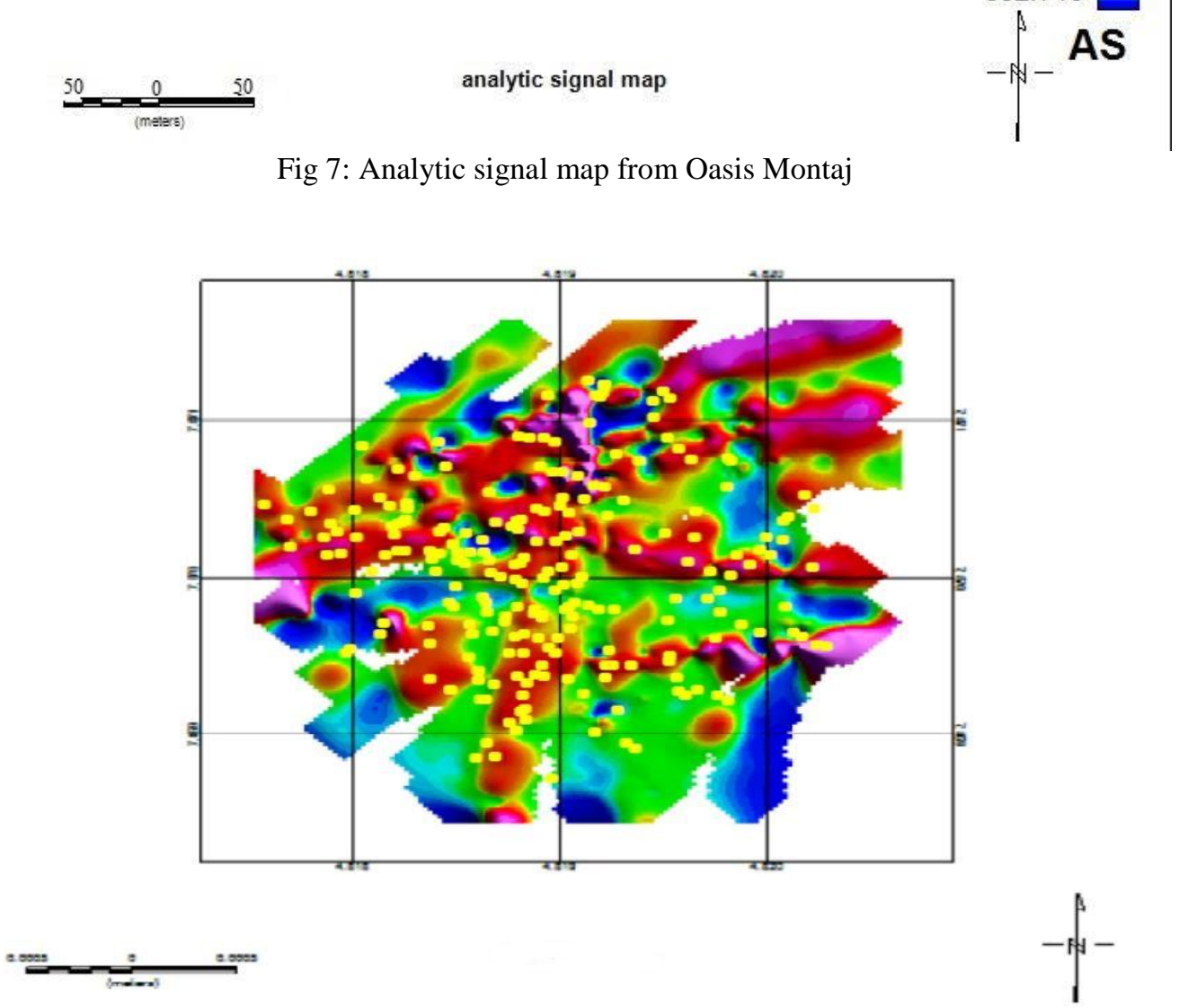

Fig 8: Trenches superimposed on magnetic map from Oasis Montaj

\section{ii. GROUND PENETRATING}

\section{RADAR}

The Ground Penetrating Radar (GPR) data were collected at a 30 meter line separation along the survey area, sixteen (16) profiles were stored and recorded, nine (9) profiles in N-S direction and seven (7) profiles in the E-W direction (Fig.9). The polarity of the reflections at the various interfaces provides information on the soil moisture of the structures and dielectric properties at the war site. Some of the GPR lines have reflection events that correlate with features seen on both the 2-D resistivity inversion and magnetics. 


\title{
International Advanced Research Journal in Science, Engineering and Technology
}

\author{
Vol. 6, Issue 4, April 2019
}

Radargram with features showing possible presence of archeological materials also falls on regions of high magnetic susceptibility from the magnetic maps (fig 10). Radar section for profiles 1, 5,6,8,11,14 shows the possible presence of artifacts at the study area, while profiles $2,3,4,7,9,10,12,13,15$ and 16 are not showing any significant features. GPR profile 1 with the possible occurrence of artifacts between the distance of $26-40 \mathrm{~m}$ corresponds with region of high resistivity value on the inversion profile 1 between the distance of $30-36 \mathrm{~m}$. Depth of penetration of the ground penetrating radar profiles appears to have reached a limit of about $2.3 \mathrm{~m}$. GPR profile lines were superimposed on the magnetic map and 8 profiles $(1,4,6,8,9,12,13,14)$ falls on regions of high magnetic susceptibility. Profiles 1 and 11 are one of the profiles showing features with possible presence of archeological materials (Fig 10-11). Positions of trenches were also identified on the radargram. (fig 12-15)

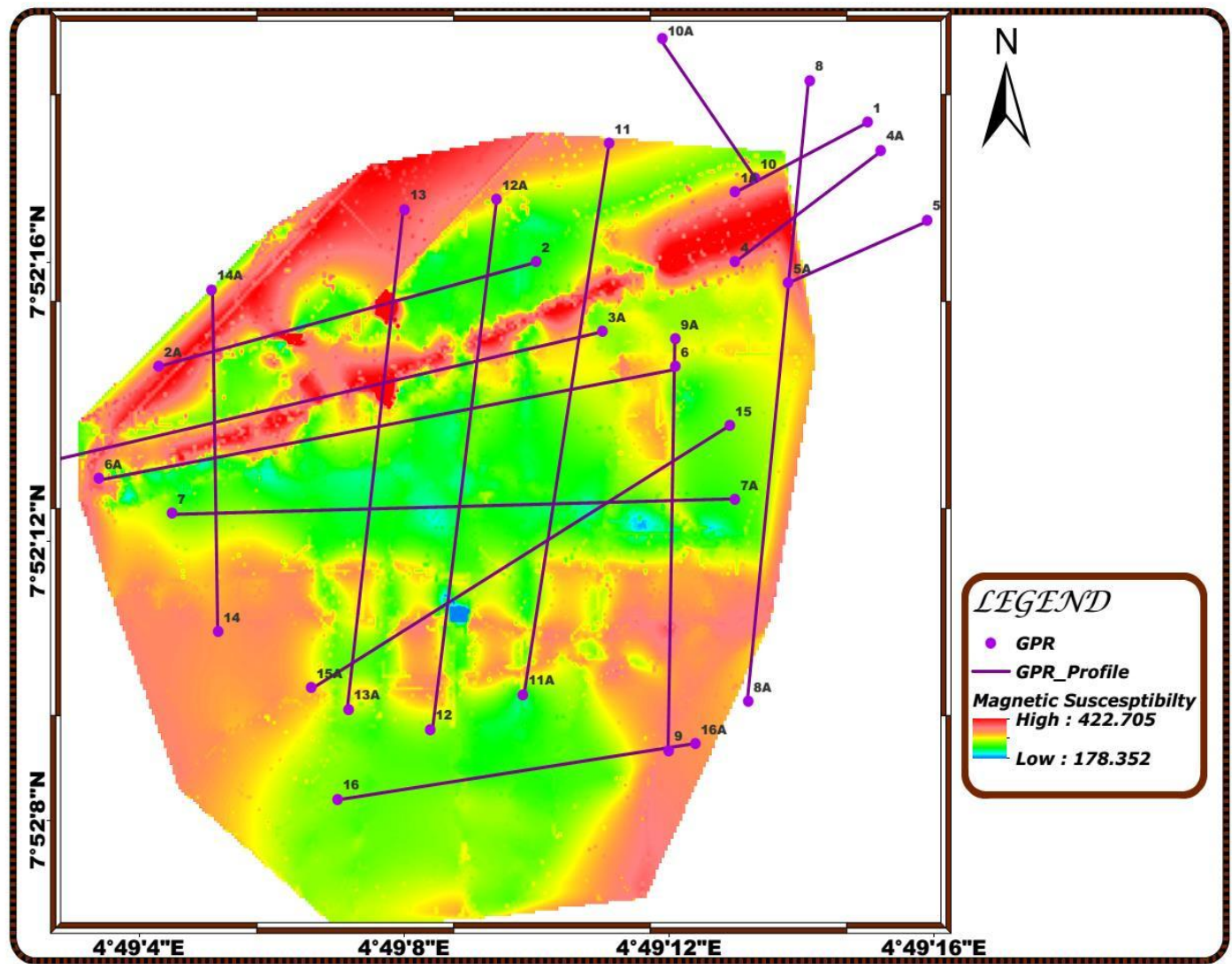

Fig 9: GPR survey pattern superimposed on magnetic map

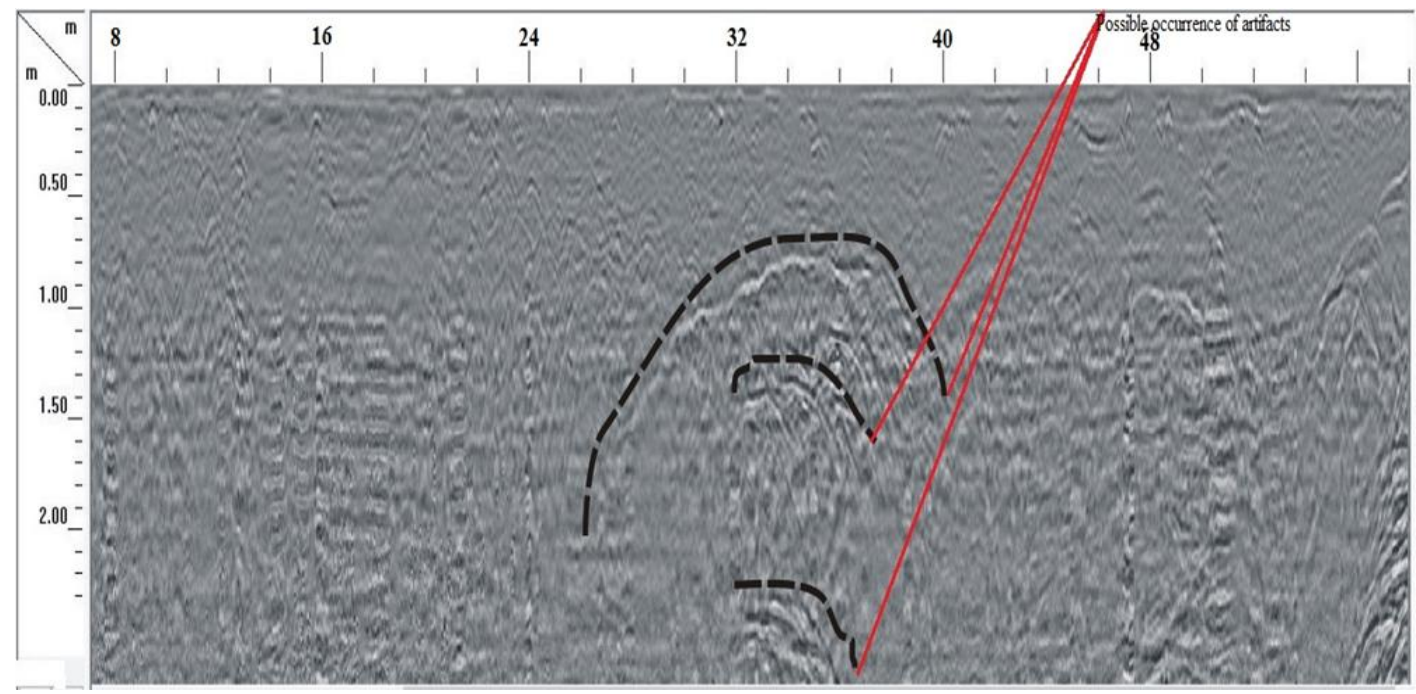

Fig 10: Radargram from profile 1 showing possible presence of archeological features 


\section{International Advanced Research Journal in Science, Engineering and Technology}

Vol. 6, Issue 4, April 2019

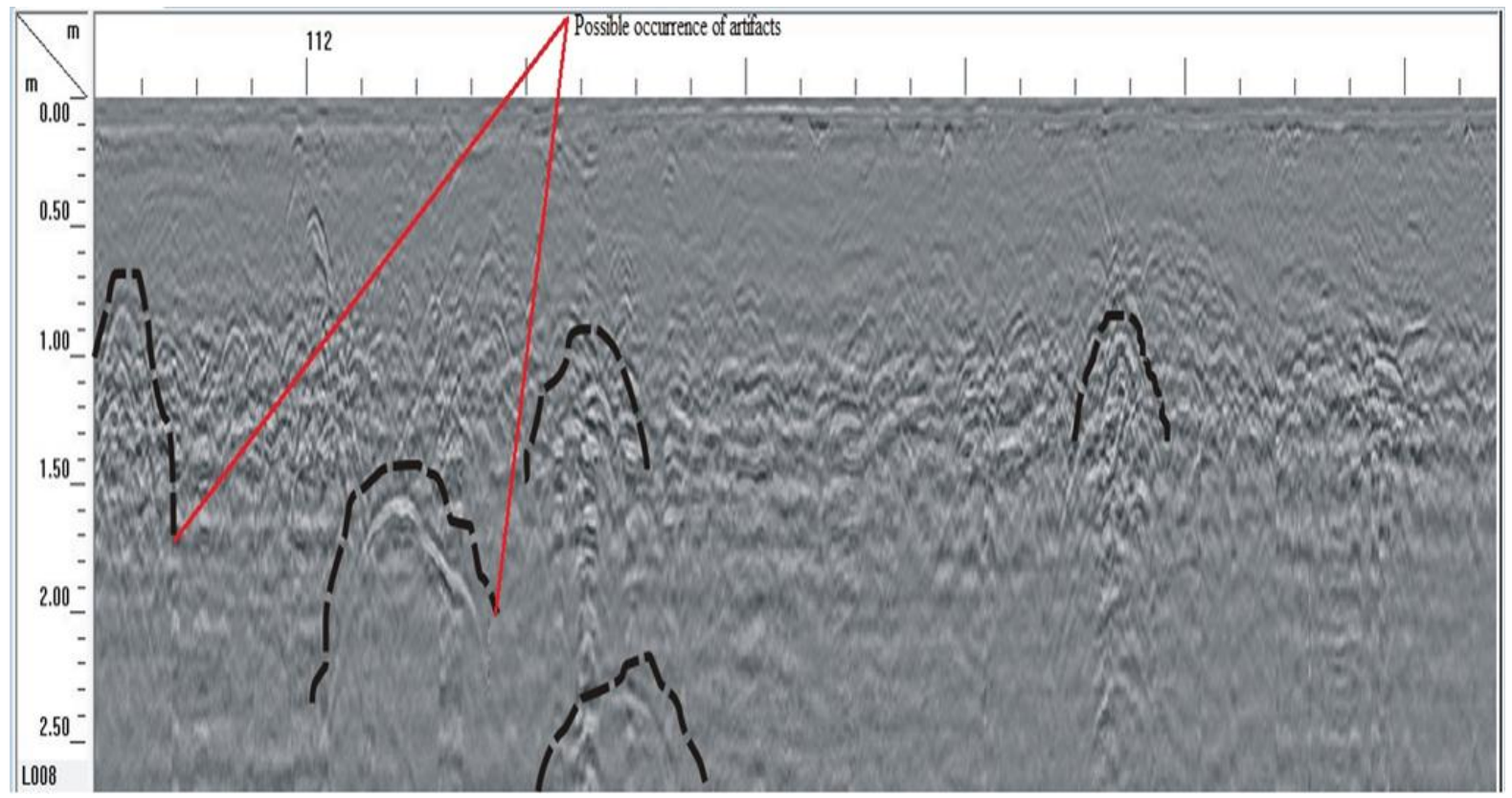

Fig 11: Radargram from profile 11 showing possible presence of archeological features

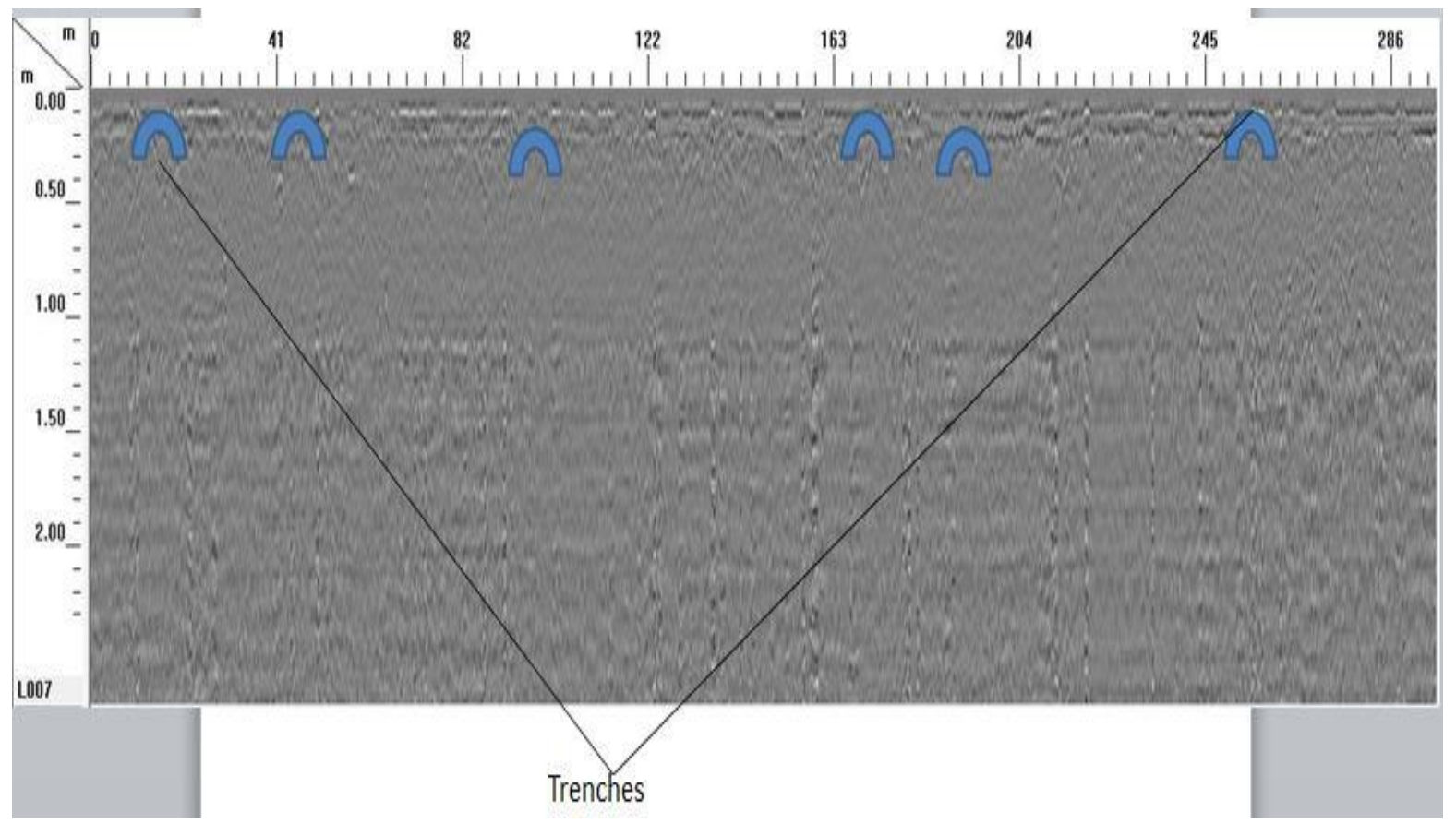

Fig 12 Radargrams of profiles 7 indicating position of trenches 
International Advanced Research Journal in Science, Engineering and Technology

Vol. 6, Issue 4, April 2019

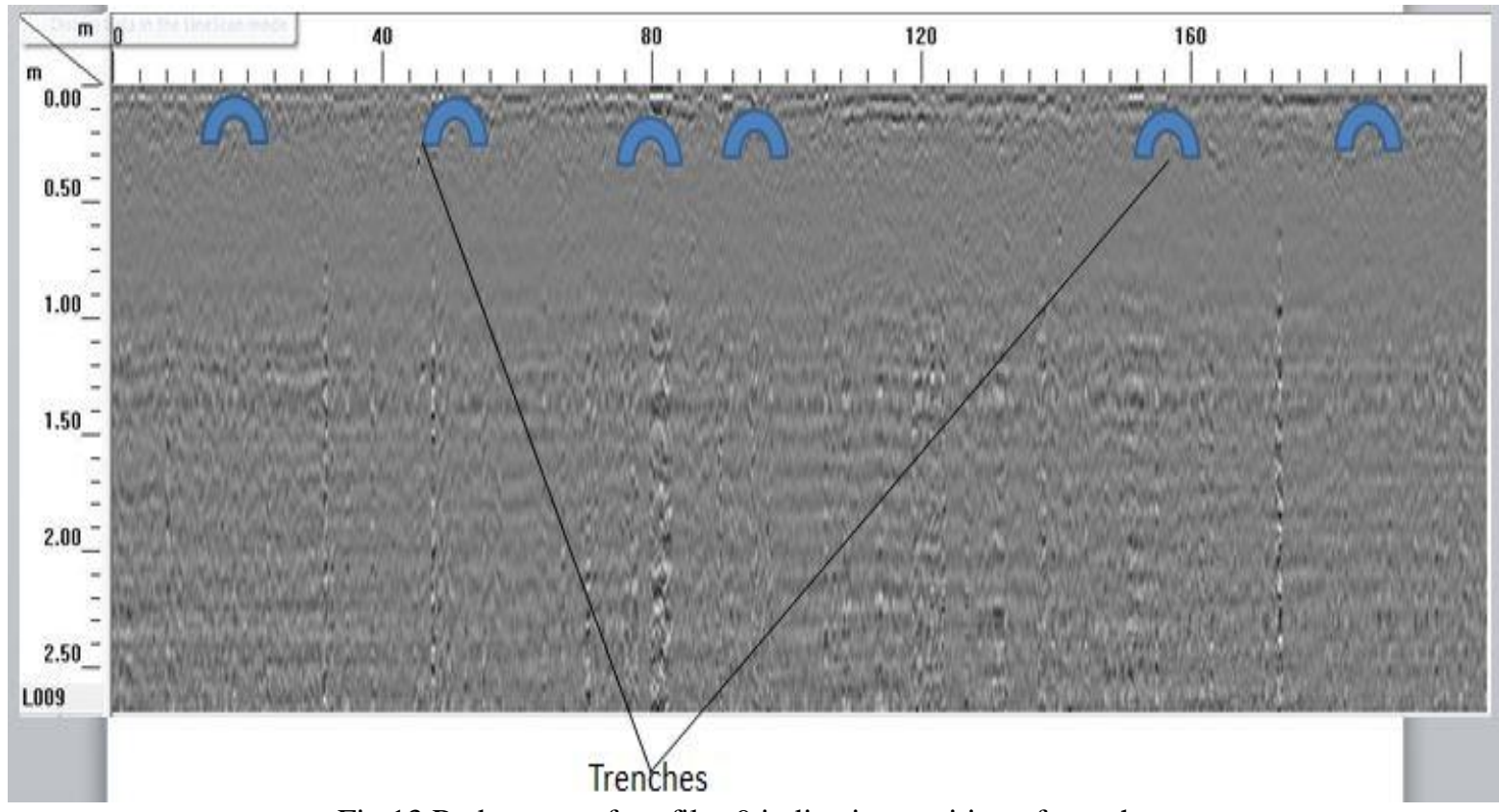

Fig 13 Radargram of profiles 9 indicating position of trenches

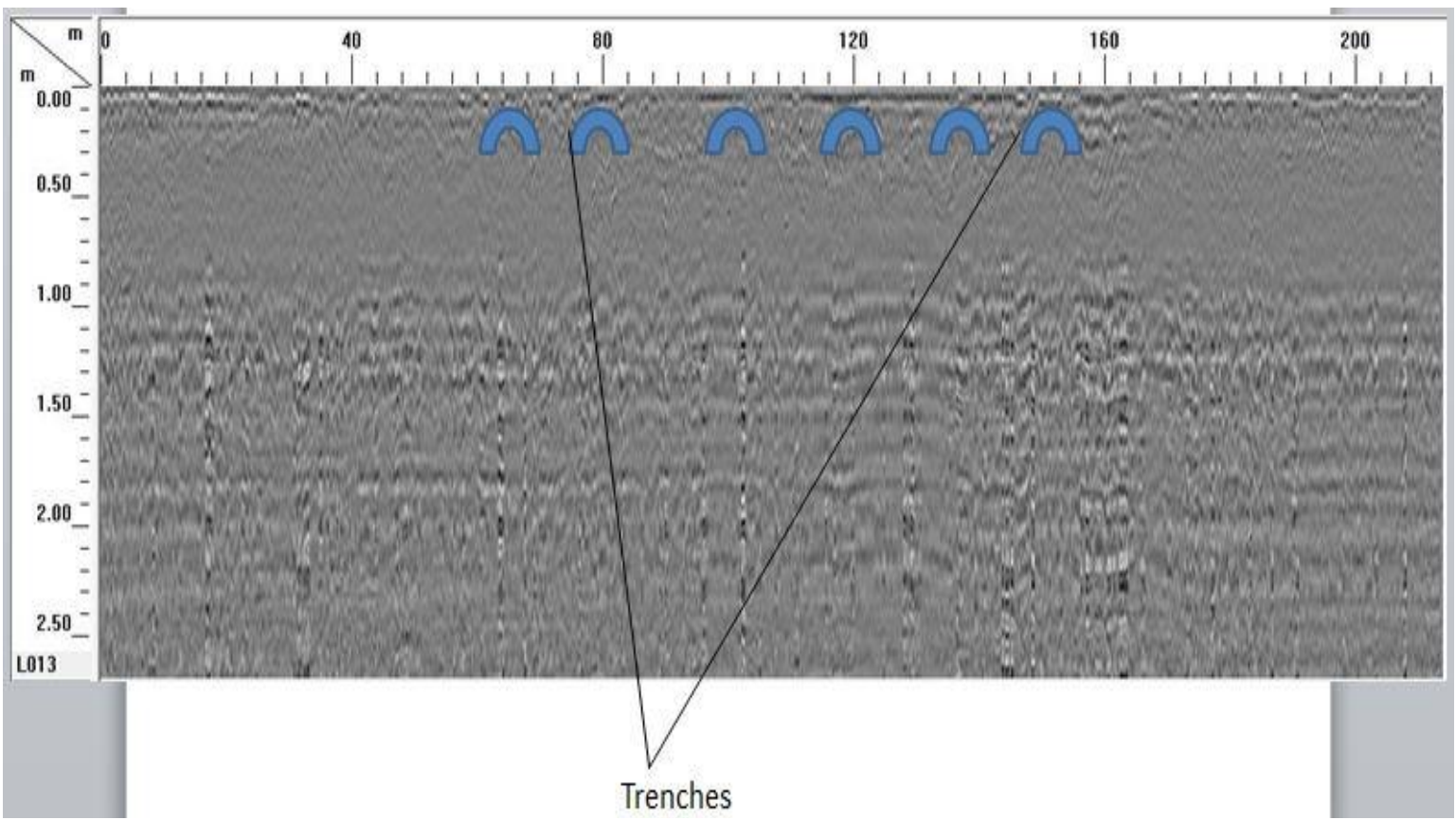

Fig 14 Radargram of profiles 13 indicating position of trenches 


\section{International Advanced Research Journal in Science, Engineering and Technology}

Vol. 6, Issue 4, April 2019

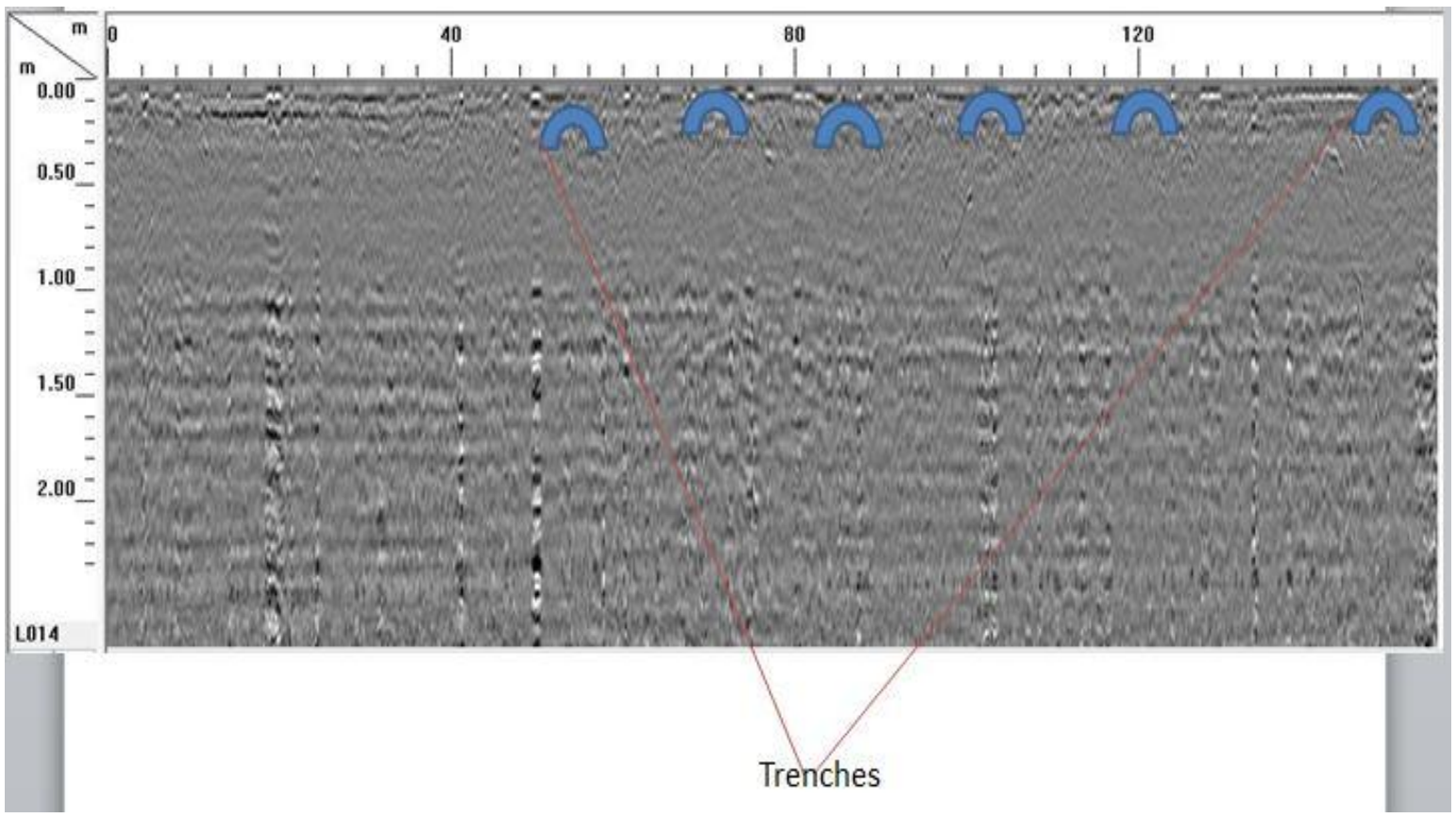

Fig 15 Radargram of profiles 14 indicating position of trenches

\section{iii. THE ELECTRICAL RESISTIVITY}

RES2DINV was the software used in the computer inversion of the 2D apparent resistivity data. This nonlinear optimization technique automatically determines $2 \mathrm{D}$ resistivity model of the subsurface for the apparent resistivity data in combination with least square inversion and smoothness constraints being applied [10].

Five (5) profiles were carefully selected based on the results of magnetic and GPR for further investigations using the electrical resistivity method. (Fig 16-20) illustrates the results of the five profiles, north-south and east-west 2D resistivity cross sections. The range of resistivity values spanned from about 41-54959 Ohm-meters. It was presumed that areas with very low resistivity, probably in the range of 41-191 Ohm-meters are mainly trenches that have been filled up by highly conductive materials. The region with the highest resistivity values varies from 510-54959 Ohm-m at depth of $0.5-3 \mathrm{~m}$ indicating the presence of archeological materials. Profiles 1,4 , and 5 with high resistivity values shows the possible presence of buried archeological material which falls within the distances of the dugged trenches with depth approximately 2-3 $\mathrm{m}$ deep in the study area.

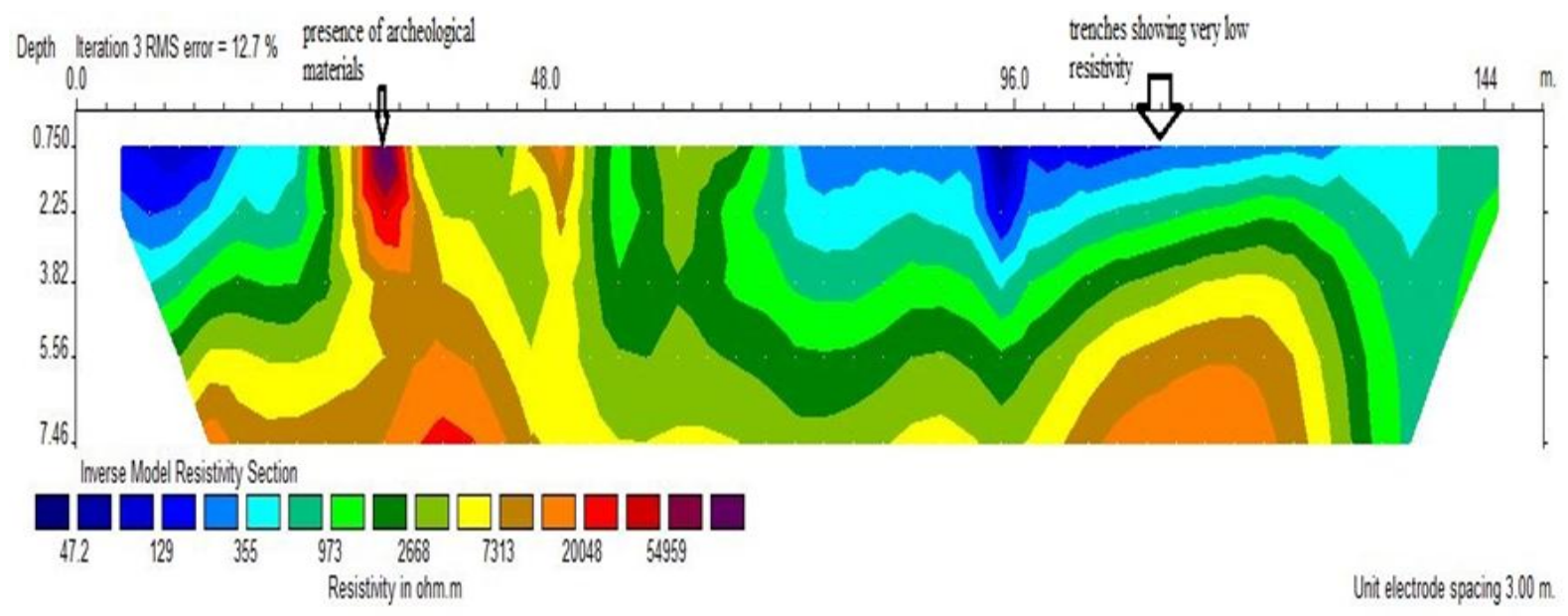

Fig.16: Resistivity inversion for profile 1 
Vol. 6, Issue 4, April 2019

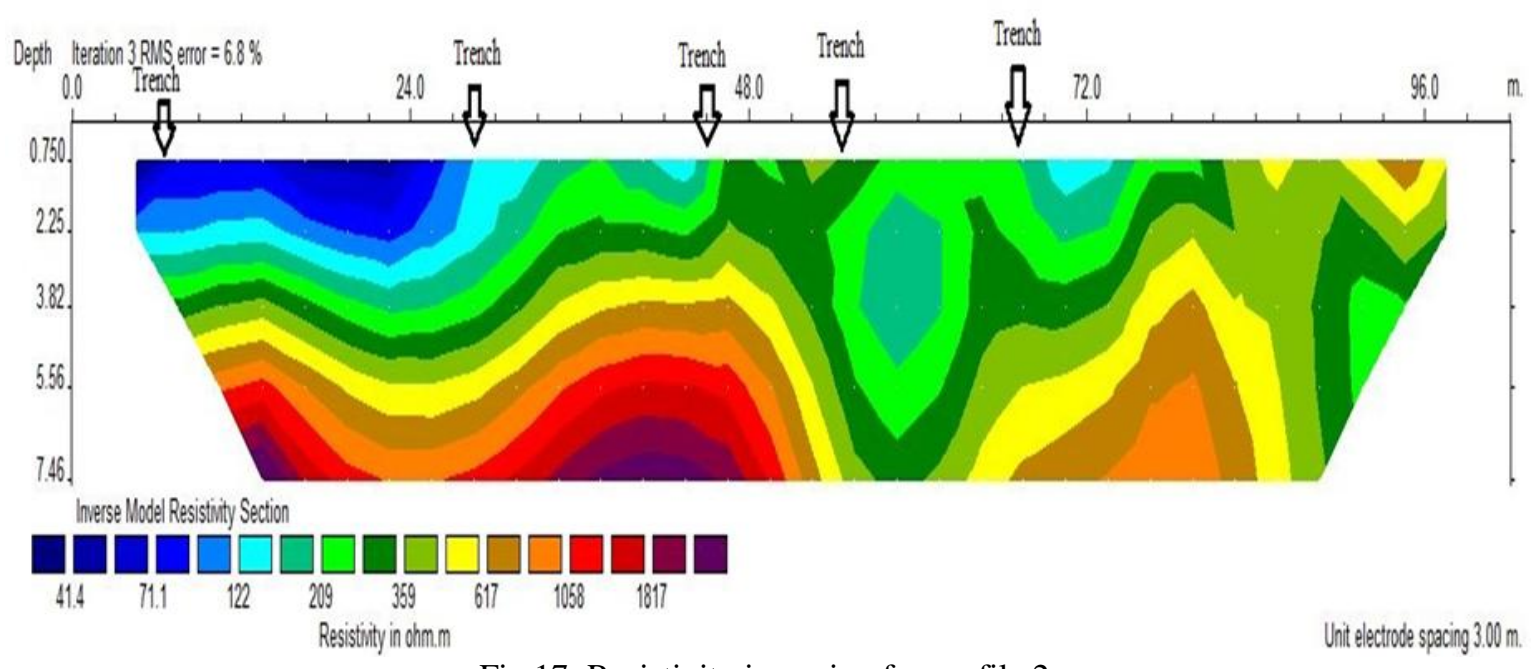

Fig 17: Resistivity inversion for profile 2
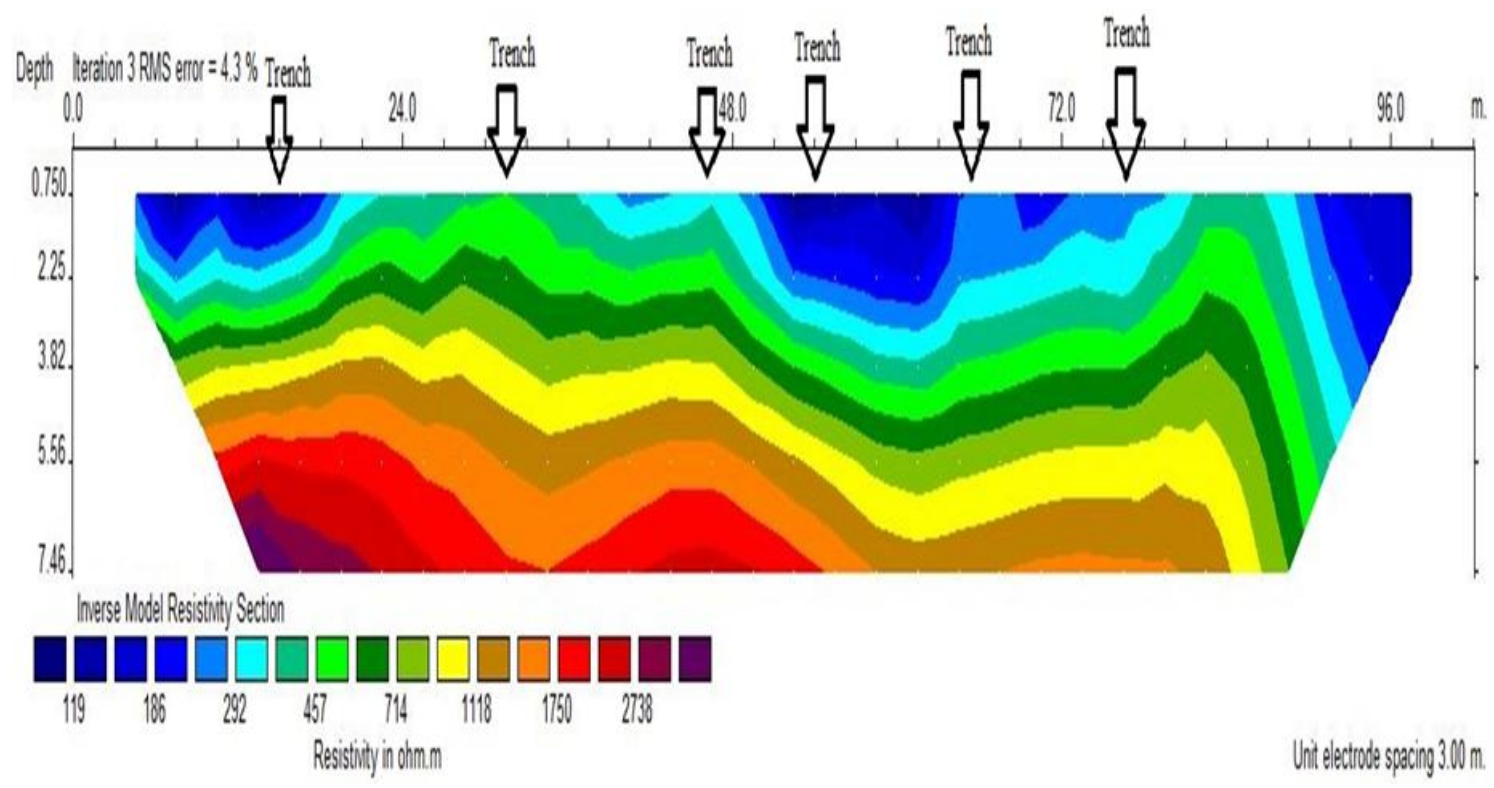

Fig 18: Resistivity inversion for profile 3

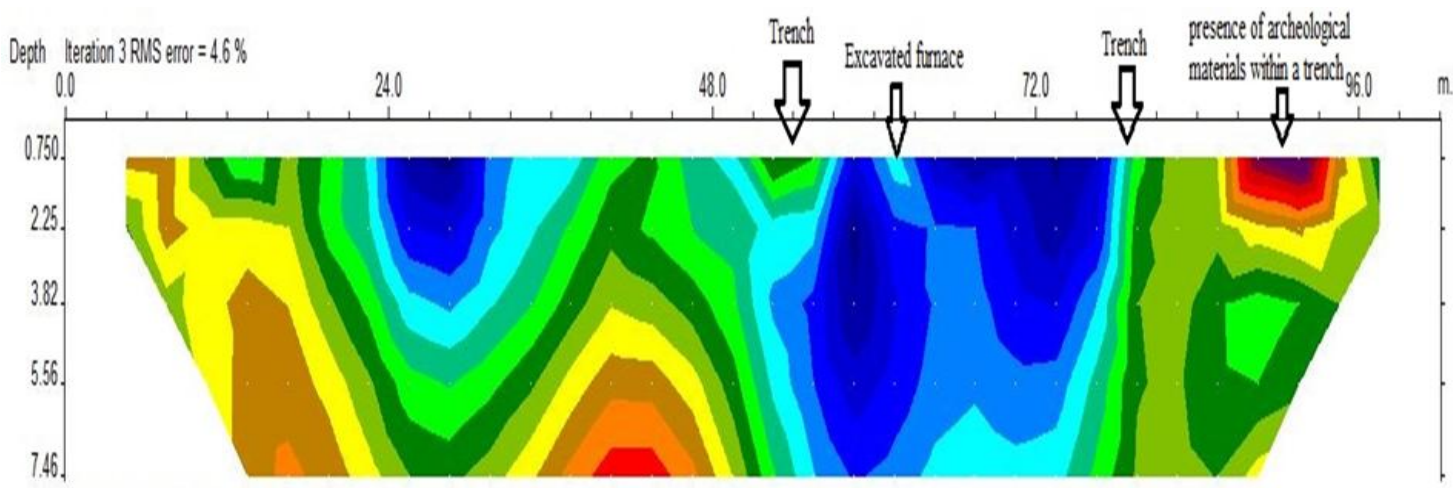

Imerse lloded Resistity Section

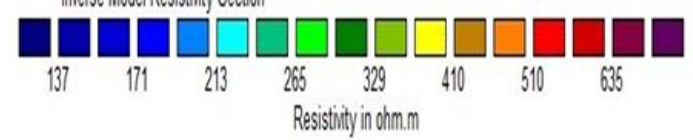

Fig. 19: Resistivity inversion for profile 4 


\section{International Advanced Research Journal in Science, Engineering and Technology}

Vol. 6, Issue 4, April 2019

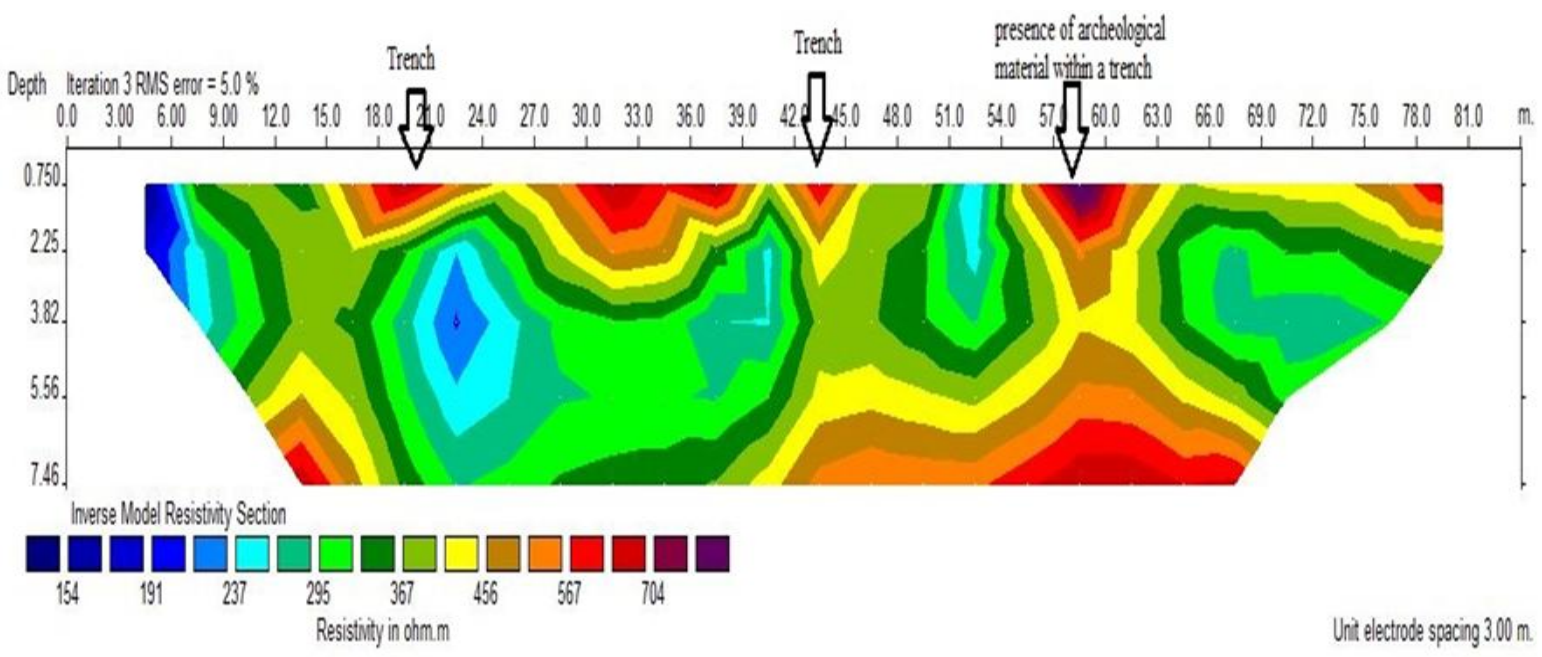

Fig.20: Resistivity inversion for profile 5

\section{CONCLUSIONS}

The integration of ground penetration radar, magnetic and electrical resistivity methods revealed detailed and cost effective identification of zones of potential archaeological interest at the theatre of war in Igbajo. The ground penetrating radar (GPR) were acquired using the GSSI SIR 3000, the magnetic method were acquired using the proton precession magnetometer while Ohmega resistivity was used to acquire the electrical resistivity data.

The applications of geophysical method to delineate the depth and locations of archaeological materials have been demonstrated. The result of the magnetic survey showed regions of high magnetic intensity which indicates the existence of certain buried artifacts; this assisted in the gridding of the ground penetrating radar (GPR) profiles. Significant features were observed on the radargram which correlates with high resistivity anomalies observed on the inversion profile. It was observed that a region of high resistivity values on the inversion coincides with the ground penetrating radar on the radargram.

The results show that the region with the highest resistivity between $510-54959$ Ohm-m and at depths between 0.5-3 $\mathrm{m}$ from the resistivity inversion indicates the possible presence of artifacts which can further be confirmed through excavation. From this study it can be confirmed that integrated geophysical methods are nondestructive and more effective in identifying buried archeological artifacts and providing information about subsurface content at archeological site.

\section{REFERENCES}

[1]. Oyeyemi K.D, Oladunjoye M.A, Olayinka A.I, and Aizebeokhai1 A.P. (2015), Geophysical Imaging of Archaeological Materials at Iyekere, Ile- Ife Southwestern Nigeria Journal of Environment and Earth Science www.iiste.org ISSN 2224-3216 (Paper) ISSN 2225-0948 (Online) Vol.5, No.2, 2015

[2]. Weymouth, J. \& Huggings, R., (1985), "Geophysics Surveying of archaeological sites", 191-235.In: G. Rapp and D.A. Gifford (eds.), Archaeological geology. New Haven: Yale University press.

[3]. Weymouth, J.W., (1985). Geophysical Methods of archaeological site surveying. In: Schiffer, M. (Ed.), Advances in archaeological method and theory, 9. Academic Press.

[4]. Forte E, Zhao W, Pipan M and Tian G (2013) "Ground Penetrating Radar (GPR) attribute analysis for archaeological prospection," Journal of Applied Geophysics, vol. 97, pp. 107-117, 10//

[5]. Mc Curry, F., (1973). Geology of Degree Sheet 21, Zaria Nigeria. Overseas Geology and Mineral resources, 45.

[6]. Clark, A. (1990) Seeing Beneath the Soil: Prospecting Methods in Archaeology. London B. T. Batsford, 160 pp.

[7]. Nabighian, M. N. (1972). The analytic signal of two-dimensional magnetic bodies with polygonal cross-section: its properties and use for automatic anomaly interpretation. Geophysics, 37: $507-517$.

[8]. Nabighian, M. N. (1974). Additional comments on the analytic signal of two dimensional magnetic bodies with polygonal cross-section. Geophysics, 39: 85 - 92 .

[9]. Roest, W.R., Verhoef, J. and Pilkington, M. (1992). Magnetic interpretation using the 3D analytic signal, Geophysics, 57 (1), $116-125$.

[10]. Griffiths, D. \& Barker, R. (1993), "Two dimensional resistivity imaging and modeling in areas of complex geology", Journal of Applied Geophysics, 29:211-226. 